\title{
A ATUAÇÃO DO SUPREMO TRIBUNAL FEDERAL NA CRISE DA POLÍTICA DOS ESTADOS NA PRIMEIRA REPÚBLICA (1908-1911): UMA ANÁLISE A PARTIR DO PERIÓDICO JURÍDICO O DIREITO
}

The performance of Brazilian Supreme Court in the crisis of the "states politics" of the First Republic (1908-1911): an analysis based on the law magazine $O$ Direito

\author{
LEONARDO SEIICHI SASADA SATO \\ E Priscila Petereit de PaOla GonçALVES
}

http://dx.doi.org/10.1590/\$2178-14942016000200006

Leonardo Seiichi Sasada Sato é doutorando em Ciência Política pelo Instituto de Estudos Sociais e Políticos da Universidade do Estado do Rio de Janeiro (IESP/UERJ) (Isaaato@yahoo.com.br).

Priscila Petereit de Paola Gonçalves é doutora em Ciências Sociais e Jurídicas pela Universidade Federal Fluminense (PPGSD/ UFF) e professora adjunta do Departamento de Direito da UFF, campus Macaé (priscilapetereit@id.uff.br).

Artigo recebido em 24 de abril e aprovado para publicação em 15 de junho de 2016. 


\title{
RESUMO
}

0 objetivo do artigo é verificar a atuação do STF, entre os anos de 1908 e 1911, frente a dois dos principais temas políticos debatidos à época: dualidades eleitorais e pedidos de intervenções federais. Utilizou-se como fonte o periódico jurídico $O$ Direito, que representou um dos principais meios de divulgação das atividades e da jurisprudência do Poder Judiciário na Primeira República. A partir de três episódios políticos documentados no periódico (Bahia em 1908, Manaus em 1910, e Rio de Janeiro em 1911), buscou-se compreender os limites da atuação do STF frente à crise da política dos estados na Primeira República.

Palavras-CHave: Primeira República; Supremo Tribunal Federal; questões políticas; periodismo jurídico.

\begin{abstract}
The purpose of this article is to observe the performance of Brazilian Supreme Court (STF) in the years 19081911 with regard to two main political issues discussed at that time: electoral dualities and requests for federal interventions. To do so, we used as a historical source the law magazine $O$ Direito, one of the main means of dissemination of the activities and jurisprudence of Brazilian Judiciary in the First Republic. Focusing on three political episodes documented in the magazine (Bahia in 1908, Manaus in 1910, and Rio de Janeiro in 1911), we tried to understand the limits of the Supreme Court during the crisis of the "states politics".
\end{abstract}

KEYwords: First Republic; Bazilian Supreme Court; political questions; juridical journalism.

\section{RÉSUMÉ}

Le but de l'article est d'observer la conduite du Tribunal Supérieur Brésilien entre les années 1908 et 1911 en ce qui concerne deux des plus importantes questions politiques discutées à l'époque: les dualités électorales et les demandes d'intervention fédérale. On a utilisé comme source historique la revue juridique O Direito, I'un des principaux moyens de diffusion des activités et de la jurisprudence du Judicaire brésilien pendant la Première République. En partant de trois épisodes politiques documentés dans la revue (Bahia en 1908, Manaus en 1910, et Rio de Janeiro en 1911), on a cherché à comprendre les limites du Tribunal Supérieur pendant la crise de la "politique des états".

Mots-CLÉS: Première République; Tribunal Supérieur; questions politiques; journalisme juridique. 


\section{INTRODUÇÃO}

$\mathrm{O}$ s periódicos jurídicos produzem e disseminam informações jurídicas, tais como novas produções legais, julgados que reforçam orientações jurisprudenciais, julgados que inauguram novos entendimentos, atos executivos, discussões doutrinárias, artigos de opinião jurídica ou política. Até não muitos anos atrás eram o meio privilegiado através do qual podiam ser acessadas as produções jurídicas mais recentes e destacadas. Entendidos como documentos históricos, formam um conjunto de fontes que desenvolveu em torno de si uma linha de pesquisa específica, a do periodismo jurídico. Essa linha foi mais desenvolvida em países como Portugal, Espanha e Itália a partir da década de 1960. No Brasil, a abordagem ainda é tênue, mas apresenta resultados. Os periódicos brasileiros têm recebido cada vez mais atenção, com os trabalhos de André Chaves (2011), Jefferson Pinto (2013), Mariana Silveira (2013) e Henrique Ramos (2009).

Andrei Koerner (2010) e Lêda Boechat Rodrigues (1965, 1968, 1991) são exemplos de autores que estudaram o Poder Judiciário brasileiro na Primeira República tendo como base periódicos jurídicos. Em seu estudo, Andrei Koerner utilizou a revista O Direito e a Revista do Supremo Tribunal Federal, além de artigos publicados no Jornal do Commercio. Antes dele, Lêda Boechat Rodrigues utilizou a revista Supremo Tribunal Federal - Jurisprudência (entre 1892 e 1898), a Revista Forense, a Revista de Direito Civil, Comercial e Criminal, a Revista do Instituto Histórico e Geográfico Brasileiro, A Tribuna, e jornais como o Correio da Manhã, - Diário de Notícias, a Gazeta de Notícias e o Jornal do Brasil. Recorreu ainda ao Livro de Atas do Supremo Tribunal Federal (manuscrito) para o período entre 1891 e 1898. Os autores recorreram a essas fontes porque jornais e revistas jurídicas eram as formas privilegiadas de se acessar informações jurídicas, ainda que defasadas em alguns meses, casual ou propositalmente, como se verá mais à frente.

Ao analisar cinco casos caracterizados como conflitos entre oligarquias estaduais ocorridos entre 1908 e 1911, Andrei Koerner considerou os resultados finais dos julgamentos para afirmar que "os votos dos ministros do STF acompanharam as posições dos chefes políticos aos quais eles eram ligados" (1998: 202). Esse argumento de que o STF e seus ministros votavam conforme as oligarquias a que estavam vinculados é perfeitamente plausível, mas pode ser complementado, conforme também se verá. 
Na linha do periodismo jurídico, pretende-se aqui analisar a atuação do STF na Primeira República a partir do levantamento de como o periódico de jurisprudência $O$ Direito abordou os seguintes temas: dualidades eleitorais e pedidos de intervenção federal. Embora intervenções federais não tenham sido raras, a estabilidade do período suscitou requisições de intervenção. Neste sentido, a atenção será focada nos periódicos jurídicos como uma fonte privilegiada para abordar os posicionamentos do STF em três casos emblemáticos da Primeira República: (i) o grande cisma na Bahia em 1907, (ii) o bombardeio de Manaus em 1910 e (iii) a sucessão ao governo do estado do Rio de Janeiro em 1911.

0 recorte escolhido corresponde à transição para o período de maior turbulência da Primeira República desde sua estabilização no governo Campos Sales (1898-1902) com a Política dos Estados ou Política dos Governadores. Serão aqui abordados, assim, alguns eventos ocorridos entre a fase de estabilidade da Política dos Governadores e o governo Hermes da Fonseca (1910-1914). Essa conjuntura histórica será abaixo delineada, para que depois sejam contextualizadas e levantadas questões referentes à fonte primária utilizada. Serão enfim abordados os casos elencados: o habeas corpus preventivo por questões eleitorais na Bahia em 1908, o bombardeio de Manaus em 1910, e a dualidade legislativa no Rio de Janeiro em 1911.

Por fim, a conclusão apontará para os seguintes argumentos: a judicialização de questões afetas à política só acontecia em estados de segunda grandeza, pois os de primeira grandeza resolviam-nas dentro de suas articulações políticas; a análise de uma história do STF não pode se satisfazer com o resultado das votações, sendo necessário compreender os argumentos e o pensamento político de cada ministro em seu contexto; deve-se levar em conta o papel da editoração dos periódicos jurídicos, que selecionavam o que viria a ser publicado e como.

\section{O CONTEXTO HISTÓRICO DA PRIMEIRA REPÚBLICA NOS ANOS 1908-1911}

ecorremos ao periódico O Direito por ter ele a pretensão de abarcar todas as questões
jurídicas do país, inclusive as estaduais, em todas as matérias, como a civil, a criminal e a administrativa. A abordagem da fonte se iniciou no ano de 1908 e se estendeu até 1913, quando o periódico deixou de ser editado. Abarcou-se assim do volume 105 ao 120. Focou-se desse modo a fase áurea da estabilidade do regime, que se estendeu da fase de consolidação republicana (1898-1902) até o governo Hermes da Fonseca (1910-1914).

Foi no período 1898-1902 que ocorreu a estabilização oligárquica, com o governo Campos Sales. Instituiu-se então a Política dos Estados ou Política dos Governadores, com 
a qual o regime atingiria seu "equilíbrio". 0 que o governo Campos Sales conseguiu foi a resolução dos impasses que urgiam desde a Constituinte de 1890-1891, quando o ultrafederalismo representava a radicalização das propostas descentralizantes, contrárias aos projetos favoráveis à União. Era a conciliação entre os que defendiam uma centralização mínima que fosse, e que em 1891 defendiam por exemplo a figura de um STF, e os que discursavam por uma descentralização total, posicionando-se a favor de uma confederação marcada pela soberania dos estados sobre a União. Marcas desse ultrafederalismo eram a designação de senadores como "embaixadores do Rio de Janeiro" (O Direito, 1908: 507) e a existência de senados e supremas cortes estaduais.

0 presidente da República governava dando autonomia e apoio aos governos estaduais, por sua vez representados por seus principais grupos oligárquicos. Sendo fraudadas as eleições, o procedimento de escolha dependia das tênues negociações entre os Executivos federal e estadual, este garantindo o apoio eleitoral, aquele garantindo a manutenção no poder. Essa estabilização era feita através dos institutos políticos do estado de sítio e da intervenção federal, mobilizados mais emergencialmente diante de casos de dualidades eleitorais. O próprio Campos Sales tinha clareza quanto ao uso desses institutos: "Tenho, pois, por dever primeiro do Executivo Federal nas relações com os Estados o escrupuloso respeito das fronteiras demarcadas pelo art. $6^{\circ}$ da Constituição, cuja necessidade foi antevista com admirável sagacidade pela sabedoria do legislador constituinte. É essa uma condição de paz interna"1 (O Direito, 1908: 97).

Assim, Campos Sales levantava restrições à figura da intervenção federal. Seu modelo "tinha por finalidade esvaziar a esfera federal do conflito político, remetendo as questões partidárias para a esfera estadual" (Lynch, 2014: 91). 0 modelo federalista de Campos Sales procurava não regulamentar a intervenção federal e maximizar os efeitos do estado de sítio. Já os liberais, representados por Rui Barbosa, defendiam a restrição dos efeitos do estado de sítio para a salvaguarda de direitos constitucionais, e tentavam regulamentar a intervenção federal para que fosse utilizada juridicamente. Desse modo ainda seria possível um arbitramento jurídico pela União sobre as querelas estaduais. Os ultrafederalistas, entretanto, acabavam fazendo uso corriqueiro desses instrumentos de exceção e, quanto menos estes fossem regulamentados, melhor poderiam acioná-los a favor de um grupo aliado e contra os oposicionistas. Ao evitar a regulamentação e manter os institutos no plano político, tentavam ainda afastar seu mérito e efeitos da apreciação do Judiciário.

Essa caracterização áurea chegou ao fim em 1910. Iniciou-se então uma terceira fase da Primeira República, marcada pela crise da sucessão de Afonso Pena, a Campanha Civilista de Rui Barbosa, e a vitória de Hermes da Fonseca. Para Lynch, " a Campanha Civilista foi assim 
o divisor de águas no estabelecimento de uma clara divisão no campo político do regime: na medida em que o candidato oficial, Hermes da Fonseca, reuniu ao seu redor a maior parte do establishment, a oposição inicial entre civilistas e militaristas evoluiu rapidamente para 0 reconhecimento oficial da oposição entre liberais e conservadores" (Lynch, 2008: 26).

0 governo Hermes da Fonseca representou uma quebra no regime, marcado por estados de sítio e intervenções federais, inclusive não oficiais. Solidificava-se o delineamento entre liberais, que davam prioridade à defesa de direitos fundamentais no processo de estabilização do Estado, e conservadores, que colocavam a defesa dos pactos oligárquicos em primeiro plano. 0 período entre 1914 e 1922 foi marcado justamente pelas tentativas de restabelecimento da Política dos Governadores através do governo Wenceslau Brás. O Pacto de Ouro Fino, de 1913, já seria uma tentativa de São Paulo e Minas Gerais fazerem frente à candidatura do gaúcho Pinheiro Machado.

Anos depois, a Reação Republicana de 1922 e o governo Arthur Bernardes vieram marcar um novo modelo de equilíbrio federativo que levava à quebra do modelo Campos Sales, e levou à reforma constitucional de 1926. As candidaturas de Nilo Peçanha, senador do Rio de Janeiro, e J. J. Seabra, presidente da Bahia, refletiam as dificuldades dos principais grupos políticos em articular suas conveniências políticas dentro dos estados menos poderosos. Além disso, a última década republicana já estaria marcada por um nacionalismo autoritário que afastava o Judiciário das questões políticas, o que viria a se solidificar em 1926 com a reforma constitucional.

Declarações de estado de sítio e intervenções federais ocorriam por ocasião de eventos emergenciais, como a Revolta da Chibata em 1910. Entretanto, eventos inerentes à lógica do sistema suscitavam o uso dos institutos de forma bem mais frequente e sistemática. Exemplos desses eventos eram as dualidades eleitorais. Sendo fraudadas as eleições, garantiam-se as alianças entre os planos estadual e federal. Acontecia, entretanto, de dois candidatos ou dois grupos se dizerem eleitos. Por se tratar de questão política a apreciação caberia ao Congresso Nacional, mas, em decorrência de sua demora, o Judiciário poderia ser acionado - entendimento esse fruto de um longo debate, uma vez que não havia disposição constitucional clara.

Foi com o objetivo de verificar como o STF se posicionava perante esses casos de intervenção federal, estado de sítio e dualidades eleitorais que foram abordados os volumes de O Direito entre os anos de 1908 e 1913. 0 argumento é de que a própria circulação desses posicionamentos formava em si uma notícia e constituía uma referência para impactar os eventos políticos em curso. Buscou-se portanto observar os posicionamentos da Corte e de seus ministros, assim como os argumentos utilizados para fundamentar suas posições, em uma linha que atenta para a publicização dessas atividades. 
0 recorte serve como filtro: não se procura o que foi judicializado, o que demandaria uma pesquisa extensa sobre os processos judiciais, mas sim o que moveu impactos políticos por sua própria existência no plano da mobilização de argumentos para a estabilização política. Importa o que chegava à esfera pública, e isso é mensurado através da circulação em periódicos de jurisprudência, que permitiam a mobilização de argumentos, ideias, teorias. As eventuais omissões e o silêncio das fontes consultadas formam mais um dado e sustentam ainda mais o argumento sobre a publicidade.

\section{O PERIÓDICO JURÍDICO O DIREITO}

revista 0 Direito, um dos mais tradicionais periódicos jurídicos, foi fundada em 1873
e teve 120 números publicados até abril de 1913. A publicação trazia notícias de atos executivos, legislação, artigos de doutrina, pareceres de comissões legislativas e, no que tange ao Poder Judiciário, decisões de tribunais estaduais, de juízes federais e do STF. Sua peculiaridade era o fato de que costumava trazer a decisão recorrida, documentos do caso, e extensos votos. Em oposição, o periódico sucessor, a Revista do Supremo Tribunal(1914-1925), dedicava-se tanto ao STF quanto à Corte de Apelação do Distrito Federal e aos tribunais superiores dos estados, mas trazia acórdãos em regra com votos curtos, sem a decisão recorrida. Em compensação, além dos artigos de doutrina e pareceres, trazia também os debates de sessões do STF.

A Revista do Supremo Tribunal é relevante por dar pistas de como eram coletados os votos dos ministros do STF. Seu primeiro número, de abril de 1914, trazia uma apresentação assinada pelo editor Astolpho Rezende (1914), que fornecia dois elementos que ajudam a compreender a constituição do gênero da fonte. Astolpho Rezende atacava os repositórios oficiais existentes nos EUA porque estes atrasavam a publicação das decisões e perdiam a clareza e a concisão. Defendia "o poder de escolher o que é substancial e desprezar o resto", o que importava em defender o poder de editar as sentenças. 0 segundo elemento se refere à própria forma de transcrição do texto. Os juízes ingleses de última instância não teriam o hábito de escrever suas decisões, pronunciando-as oralmente. Elas eram assim viciadas por um tom de conversação e de repetição. Os Justices norte-americanos, ao contrário, trariam os votos escritos para lê-los objetivamente num estilo dogmático sem apologias, e essa leitura é que seria transcrita pelos editores.

O Direito não devia adotar procedimento muito diferente. Os votos a serem publicados eram transcritos a partir da leitura pelos julgadores. Mesmo que transcritos, desenvolveu-se a suspeita de que no processo de edição alguns votos poderiam ser selecionados, e não se reproduziriam todas as discussões travadas, o que fica claro a partir de algumas atas de sessões 
disponibilizadas. Não parecia convincente que o ministro Pedro Lessa, um dos criadores da doutrina brasileira do habeas corpus, se mantivesse calado frente aos votos de Epitácio Pessoa, que só admitia o remédio para a estrita salvaguarda do direito de locomoção.

A seleção de votos para publicação veio a ser confirmada através de um volume especial de 0 Direito. 0 volume 111, de 1910, p. 422-430, trazia o segundo acórdão na Ação Originária 7, em que o estado do Paraná levantava embargos quanto à competência do STF, ao quórum mínimo de ministros ao considerar que o presidente não poderia compô-lo para contagem, e ao princípio do uti possidetis para que tivesse direitos sobre territórios catarinenses. Tratava-se da questão dos limites entre os estados de Santa Catarina e Paraná, que viria a resultar na Guerra do Contestado. Os longos "considerando" do relator André Cavalcanti, na véspera do Natal de 1909, afirmavam a competência do STF, afastavam o princípio do uti possidetis para casos de limites entre estados da União, e consideravam válido o cômputo do presidente da Corte para o quórum mínimo de 10 ministros para julgar a questão.

Os votos do STF na Ação Originária 7 fugiram ao padrão de 0 Direito. A revista trazia peças processuais, sentenças recorridas, a íntegra do acórdão, mas raramente trazia detalhes sobre os votos dos ministros. Quando o fazia se restringia a apontar o ministro vencido, ou alguma frase que ressaltasse algum ponto específico do voto. No caso, entretanto, o ministro vencido Manoel Espínola trazia um voto que ocupava duas páginas da revista. 0 voto de Raul Martins ocupava 1/3 de página, e o de Godofredo Cunha tinha seis linhas, o que já fugia do padrão de votos curtos registrados no periódico.

Observa-se que o voto de Godofredo Cunha era publicado depois do de Raul Martins, embora este seguisse o daquele. Ou seja, a publicação não seguia a ordem das votações. A votação foi arriscada o suficiente para tornar relevante uma nota no resumo do julgado, em que o editor de 0 Direito dizia que "entre os dez ministros do Supremo Tribunal para julgarem as causas de que cogita a lei 938 de 1902 se comprehende o Presidente do Tribunal" (p. 422), cujo voto poderia vir a fazer diferença. 0 resultado final foi 7 a 4, sem 0 voto de Guimarães Natal, para quem havia a anotação "fui presente".

Fora do espaço destinado ao acórdão, esse mesmo volume 111 trazia na seção de doutrina o voto do ministro Pedro Lessa na mesma Ação Originária 7. 0 texto de 18 páginas é muito significativo, uma vez que era publicado como doutrina no mesmo volume em que estava sendo veiculada a decisão do STF, no qual deveria ter sido retratado na forma de voto.

Fosse no processo de transcrição, fosse na seleção de casos para publicar, fosse na edição, alguns votos mereceriam destaque em detrimento de outros, salvo se publicados posteriormente enquanto doutrina, ou quiçá em outra revista de diferente orientação jurídica. Isto ocorria porque os processos não circulavam, não atingiam o público em geral. Mesmo a 
constituição dos votos no acórdão representava o que os ministros queriam fazer registrar, a partir do que os editores decidiam sobre quando e como publicar. Nada impedia, então, que essas revistas tivessem inclinações por correntes jurídicas e políticas, como efetivamente era o caso de $O$ Direito. Isto posto, cabe abordar os episódios escolhidos para análise.

\section{HABEAS CORPUS PREVENTIVOS NAS ELEIÇÕES BAIANAS DE 1908}

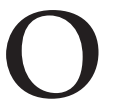

s casos baianos (O Direito, 1909: 508-514) foram os que menos ensejaram discussões e os que apresentaram os votos mais objetivos. Isso pode ter se dado pela urgência e distância da situação em que foram pedidos habeas corpus (HC) preventivos via telegrama ao STF (Koerner, 1998: 196). A origem do problema residiria na divisão do Partido Republicano Baiano, que foi chamada de "grande cisma de 1907". Na ocasião formaram-se os severinistas, ao lado do senador e ex-governador Severino Vieira, e os marcelinistas, ao lado do governador José Marcelino de Sousa (Quadros, 2011b). Na eleição do sucessor deste viria a vencer João Ferreira de Araújo Pinho, um marcelinista (Quadros, 2011a). Antes disso, o presidente Afonso Pena, apoiador dos marcelinistas, entrara em acordo com Pinheiro Machado para afastar líderes políticos hostis como Nilo Peçanha. No contexto das eleições baianas, José Marcelino de Sousa tinha assim o apoio do governo federal, de Pinheiro Machado e de Rui Barbosa, o que motivaria os severinistas a pedirem habeas corpus preventivos. Segundo as conclusões de Koerner (1998), esses habeas corpus seriam julgados conforme as vinculações oligárquicas dos ministros.

Uma pequena série de habeas corpus foi impetrada no STF. Os habeas corpus 2520 e 2519 foram pedidos em defesa dos deputados estaduais Antonio Alexandre Borges dos Reis e Carlos Gonçalves Fernandes Ribeiro. Respectivamente a 27 e 26 de março de 1908 o STF concedeu a ordem para garantia de liberdade individual e exercício de funções legislativas. Vencidas as preliminares quanto à competência do tribunal e à dispensa de informações do juiz e do governador, a votação foi exatamente a mesma: Pindahiba de Mattos vice-presidente, Epitácio Pessoa com voto vencedor, Guimarães Natal, André Cavalcanti, Manoel Murtinho, Ribeiro de Almeida e João Pedro deferiram, ficando vencidos Pedro Lessa, Cardoso de Castro, Espírito Santo e Amaro Cavalcanti. No HC 2533, do dia 27, a única diferença foi que não venceu a preliminar por dispensa de informações. Ainda assim houve a mesma votação, devido à urgência do assunto. Este é um indicativo de que os ministros estariam a votar coerentemente.

Outro habeas corpus, o 2517, foi pedido para o "senador no estado da Bahia" 2 João Moreira de Pinho, que se dizia impedido pelo governador de comparecer à sessão de 28 de março de 1908 para apurar a eleição para governador. Pedia o HC por sua "liberdade 
individual de modo que elle possa exercer livremente as suas funcções constitucionaes". Sob os mesmos argumentos o STF considerava que a concessão não acarretaria mal, mas o contrário sim, e com a mesma votação deu a ordem. E o mesmo acontecia nos HC 2534 e 2535 para o senador estadual Themistocles Passos e o deputado estadual Augusto de Araujo Santos. A única diferença era que este último alegava que a assembleia iria se reunir para reconhecimento de poderes do governador. Sob a mesma causa e com o mesmo desfecho houve o HC 2536, com os pacientes vigário José Cupertino de Lacerda, Leopoldino Antonio de Freitas Tantú, Joaquim dos Reis Magalhães e José Abrahão Cohin, presidente, vice-presidente, 1ำ e 2ำ secretários da Assembleia Geral do estado.

Por fim, os pacientes poderiam ser severinistas, mas todos eram signatários de um telegrama enviado a Rui Barbosa em 31 de março de 1908, embora Rui estivesse a apoiar justamente os marcelinistas, segundo Koerner (1998: 196). Nele, pediam "intervenção vosso apoio moral defesa constituição honra Bahia". Diziam estar sofrendo violências do governador, que os forçava a apurar as eleições de 127 municípios em três horas em recinto com capangas armados. Mesmo que fosse um recurso de desespero, isso só mostra que as alianças oligárquicas eram muito frágeis.

Nenhum desses casos baianos trouxe discussões, votos divergentes e nem mesmo o voto vencedor de Epitácio Pessoa. Todos foram curtos e publicados no mesmo volume. Não se discutia a prova da coação, se era ilegal, se a questão política afastava a apreciação do Judiciário, se era uma intromissão na separação de poderes, ou se a leitura sobre autores estrangeiros poderia sustentar a tese. Sem debates acalorados, é cabível a análise de que os ministros votassem conforme suas vinculações oligárquicas. De todo modo, em meio à estabilidade da Política dos Estados, sequer se cogitou de intervenção federal, e o STF deferiu os HC preventivos, mesmo que não por unanimidade.

\section{O BOMbardeio de MANAUS EM 1910 EM O DiREITO}

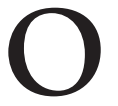

s volumes de 1912 traziam casos referentes à política no Amazonas, que geraram dois processos: o HC 2950 e o HC 3088, do STF (O Direito, 1912: 582-585). 0 governador era Antônio Clemente Ribeiro Bittencourt, com mandato de 1908 a 1912. Tinha vencido a eleição para senador em 1903, que fora anulada em prol de José da Costa Azevedo na Comissão dos Cinco, devido à acirrada oposição de Pinheiro Machado. Em 1904 fora vice-governador do estado, e quatro anos depois fora enfim eleito governador com o apoio do presidente Afonso Pena, mas sempre sob forte oposição de Pinheiro Machado e da liderança local da família Nery. Apoiou a Campanha Civilista de Rui Barbosa em 1909, e no ano seguinte viu Manaus ser 
bombardeada, sendo forçado a se retirar para Belém. Conseguiu retomar o governo através do habeas corpus do STF mas não encerrou o mandato, vindo a ser deposto em dezembro de 1912 por um golpe militar.

O HC 3088 dava um panorama. Era impetrado em favor de Fernando de Castello Simões, Adolpho José Moreira, e os coronéis Domingos José de Andrade, Hildebrando Luiz Antony e Joaquim Cardoso de Farias, deputados do "Congresso do Estado do Amazonas". Os pacientes reconheciam ter cometido um crime político, e por isso deveriam ser julgados pela Justiça Federal, conforme o art. 60 da Constituição. Mesmo confessos, reclamavam por sofrer constrangimentos ilegais ao serem processados na Justiça Estadual e não na Federal. 0 crime dos pacientes consistia em terem se reunido a 7 de outubro de 1910 no cruzador Comandante Freitas, "onde forjaram uma acta de pretensa sessão do Congresso, na qual se diz ter sido declarado vago o cargo de governador, por incompatibilidade do coronel Antonio Ribeiro Clemente Bittencourt, e, com este documento falso, obtido a intervenção armada do inspector da região militar (...) para a deposição daquelle governador" (O Direito, 1912: 626). Em 8 de outubro de 1910 Manaus era bombardeada por navios, e soldados tomavam o palácio, como se fosse uma intervenção federal, embora forjada. Um ano depois, a 6 de setembro de 1911, o STF deferiu por unanimidade a ordem pedida.

Refugiado em Belém, o governador Bittencourt impetrou o HC 2950, em que afirmava ter sido coagido a se retirar do palácio do governo por forças federais. 0 relator Pedro Lessa aproveitou o absurdo da situação para salientar o cabimento do habeas corpus mesmo para questões políticas, desde que houvesse ameaça ilegal à liberdade individual. A 15 de outubro de 1910 concedia-se a ordem, com a ênfase de Amaro Cavalcanti de que a decisão não contradizia votos anteriores. $O$ único voto contrário era de Godofredo Cunha, que considerava não caber o HC porque a coação era alheia à União, já estando garantida a liberdade do paciente.

0 bombardeio não tinha nenhum dos requisitos formais da intervenção federal, mas seu efeito era o de interferir na política doméstica dos estados fazendo uso inclusive de força militar federal. Em 1913 o jornal O Imparcia/ publicava entrevistas com comandantes lotados em Manaus sobre o bombardeio. 0 coronel Pantaleão Telles, comandante do 46ํㅡ Batalhão de Caçadores, afirmava já ter saído do Rio de Janeiro com orientações do presidente Nilo Peçanha para reconciliar Silvério Nery e Antônio Bittencourt. Com as negativas deste, era ventilada a ideia de destituir o governador a força. 0 comandante Costa Mendes, capitão do porto de Manaus, foi encarregado do comando da flotilha pelo ministro da Marinha, almirante Alexandrino, para que servisse à família Nery e desse suporte à deposição (O Imparcial, 1913: 6).

Esses depoimentos mostram oficiais compromissados com a intervenção federal na política estadual, mesmo que de forma ilegal. A unanimidade do STF no HC 3088 parece 
indicar menos um igual compromisso de todos os ministros, e mais a aplicação direta do dispositivo constitucional. Ilustrativo mesmo foi o HC 2950, em que os ministros deferiam uma ordem com os efeitos simbólicos que fossem, e mesmo nesse aspecto sob a oposição apenas de Godofredo Cunha, que parecia não se importar com o uso ilegal de forças federais para intervir na política de estados. Opunha-se ao voto do relator, ministro Pedro Lessa, que no acórdão aproveitava para registrar uma concepção que fazia alargar o cabimento do habeas corpus: "Se o Poder Judiciário deixasse de proteger a liberdade individual, sempre que esta fôsse ofendida por uma coação ilegal, pelo fundamento de se envolver na espécie uma questão de ordem política, por êsse modo anularia um dos principais benefícios do habeas-corpus. 0 que é essencial para a concessão do habeas-corpus é que o direito ofendido, ou ameaçado, seja a liberdade individual, ou de locomoção, e que a coação seja ilegal, hipótese exatamente verificada nestes autos" (Rodrigues, 1968: 169).

\section{O DiREITo E A DUALIDAdE DA ASSEMBLEIA LEGISLATIVA DO ESTADO DO RIO DE JANEIRO (1911)}

sucessão de Alfredo Backer no governo do estado do Rio de Janeiro foi também atra-
vessada por eventos ásperos. 0 volume 117 de O Direito, de 1912, trazia o Decreto n. 222, de 3 de agosto de 1911, que reconhecia a legitimidade da presidência de Joaquim Mariano Alves Costa na ALERJ e também autorizava o Executivo proceder à intervenção federal no Rio de Janeiro sob a hipótese do n. 2 do art. 6ํ da Constituição, ou seja, para manter a forma republicana federativa. Um decreto autoritário, que visava solucionar de vez a dualidade de assembleias em 1910.

A eleição de Hermes da Fonseca nas eleições presidenciais de março de 1910 dividia as forças políticas fluminenses, que lançaram duas candidaturas ao governo do estado. Em julho seguinte, cada grupo da assembleia proclamou eleito um presidente diferente. No último dia do ano Paulino José Soares de Souza e Mario da Silveira Vianna impetraram habeas corpus em nome da ALERJ, ou melhor, em nome do grupo de deputados que reconheceu e proclamou Manoel Edwiges de Queiroz Vieira como presidente do estado do Rio de Janeiro. 0 grupo oposto defendia o nome de Francisco Chaves de Oliveira Botelho no Executivo e de Joaquim Marianno Alves Costa na presidência da ALERJ, lado para que pendeu o decreto interventivo citado.

O caso foi de tal magnitude que O Direito publicou a petição inicial do HC 2984. Os impetrantes diziam que a 29 de dezembro de 1909 o presidente do estado Alfredo Backer recebera ordens do presidente da República de aquartelar as forças estaduais para que forças 
federais ocupassem repartições públicas, inclusive o palácio de governo. Fechado também o edifício da assembleia, o grupo paciente não podia entrar em sessão para empossar o presidente Manoel Edwiges. A mesa da assembleia ainda chegou a tentar transferir a sessão, mas o presidente do estado informava estarem ocupadas todas as repartições, e a população se negava mesmo a alugar espaços privados.

Segundo o presidente da República, a medida era necessária por perigo à ordem pública frente à presença de "grande quantidade de explosivos e uma metralhadora dominando a entrada do mesmo palacio; de que lavram na força militar do Estado radicaes divergencias, prontas a explodirem no momento da posse do novo presidente" (O Direito, 1912: 460). No dia seguinte o STF concedia a ordem de habeas corpus em favor do grupo de Manoel Edwiges. O presidente Hermínio do Espírito Santo se declarava suspeito. Deferiam a ordem o presidente interino Ribeiro de Almeida, o relator ad hoc Amaro Cavalcanti, Oliveira Ribeiro, Canuto Saraiva, Manoel Espínola, Manoel Murtinho e Pedro Lessa, que denunciava não se tratar de intervenção, mas de uma violência indefensável contra a Constituição. Isso porque a hipótese do n. 2 do art. 6o sobre manutenção da forma republicana federativa era a única que não podia dispensar a manifestação do Congresso Nacional.

Os "considerandos" de Amaro Cavalcanti abordavam a distinção das questões essencialmente políticas. Reconhecia serem estas alheias ao exame judicial, embora houvesse pontos em que competiam concorrentemente com a função do Judiciário no que tangenciava direitos e garantias individuais. Tal posicionamento já fazia reconhecer que o Judiciário (e o STF) poderia conhecer algumas questões políticas.

Entre os vencidos estavam Guimarães Natal, André Cavalcanti, Leoni Ramos, Muniz Barreto e Epitácio Pessoa. Para estes dois não estava provada a violência ou coação, e o habeas corpus deveria ser restrito à liberdade individual, não sendo cabível para provimento de funções legislativas. Outros casos em que a coação não estava provada teriam sido deferidos pelo Tribunal graças ao seu próprio cuidado de mostrar que os fatos eram notórios através de jornais e discussões parlamentares. Mesmo que tivesse sido real, a coação já estaria superada, e por isso não mais atual.

Por fim, o ministro Epitácio Pessoa ainda debochava dos argumentos de Pedro Lessa, que citava Bryce e João Barbalho para sustentar que o Congresso deveria ter sido consultado. Pessoa defendia que mesmo na defesa da forma republicana e federativa o presidente da República poderia realizar a intervenção como solução urgente. Se tivesse havido intervenção federal o Judiciário estaria obrigado a reconhecer unicamente os direitos da assembleia declarada legítima pelo presidente; sem intervenção nenhuma das assembleias poderia se dizer constrangida. Fica claro que Pessoa, ex-ministro da Justiça, da Indústria, Viação e Obras 
Públicas, ex-procurador-geral da República, e que viria a ser senador e presidente da República, tinha uma concepção que concentrava poderes no presidente, em especial perante o STF e contra Pedro Lessa. E acrescentava: "Para proval-o não preciso citar outros escriptores além dos mesmos Bryce e João Barbalho, tão contraproducentemente invocados por aquelles que defendem a competencia exclusiva do poder legislativo. (...) Pouco importa que da questão se tivesse já ocupado o Poder Legislativo" (O Direito, 1912: 492-493).

0 deferimento da ordem não fora suficiente. No dia seguinte, 5 de janeiro de 1911, 0 ministro da Justiça e Negócios Interiores enviou ofício ao presidente do STF dizendo não ter recebido nem comunicação nem cópia do teor do julgamento, e informando que, enquanto o Congresso não deliberasse, o presidente da República reconhecia e tratava apenas com o governo de Oliveira Botelho. Na prática isso significava não cumprir o acórdão do STF.

Na sessão de 11 de janeiro de 1911 o presidente Hermínio do Espírito Santo informava o recebimento de telegrama de Modesto de Mello, presidente da Assembleia protegida pelo habeas corpus, em que afirmava ainda estarem sendo impedidos de ingressar no edifício pelo chefe de polícia e pelo comandante militar. 0 ministro Ribeiro de Almeida informava ter recebido telegramas do juiz federal no Rio de Janeiro, que pedia instruções para dar execução à ordem de habeas corpus. Os deputados não conseguiam acesso à Secretaria Geral do estado sob a frágil alegação de que lá então estava a funcionar o Juízo dos Feitos da Fazenda.

Como resposta, o ministro Muniz Barreto propunha comunicar os exatos termos do acórdão. Já Epitácio Pessoa propunha que "o Tribunal declarasse inexequível, o accórdão em questão, por já ter sido o conflito do Estado do Rio competentemente resolvido pelo Poder Executivo" (O Direito, 1912: 469). Esta proposta venceu com o apoio de Muniz Barreto, Leoni Ramos, Godofredo Cunha, Guimarães Natal e André Cavalcanti, além do propositor. Contrários ficaram Canuto Saraiva, Pedro Lessa, Manoel Espínola, Amaro Cavalcanti e Manoel Murtinho.

Na sessão seguinte Amaro Cavalcanti fazia questão de que constasse em ata que "votei contra a indicação do Sr. ministro Epitacio Pessôa, por ser ella ilegal na fórma e carecedora de razão no fundo" (O Direito, 1912: 470), por ser indevida a anulação de acórdão por simples indicação de um ministro e por considerar não ter havido intervenção uma vez que inexistira 0 ato solene. Apontava ainda que mesmo uma ocasional maioria não poderia proferir aquela indicação.

Como resposta o ministro Epitácio Pessoa pedia que se fizesse constar em ata a íntegra da indicação por ele proposta. Entre vários "considerandos", fazia a sentença perder eficácia por perda de objeto para mandar arquivar os telegramas recebidos sobre a inexecução da ordem. Na sessão seguinte, de 18 de janeiro, Epitácio Pessoa indicava não ter podido o ministro Amaro Cavalcanti ler suas declarações, e delas tomando conhecimento ainda fez 
constar que sua proposta nada tinha de ilegal na forma nem rra carecedora de razão no fundo. Sem mais poder fazer, Pedro Lessa apenas fazia questão de que se registrasse na ata estar de acordo com a declaração de Amaro Cavalcanti.

Estava feita uma intervenção tão discricionária e autônoma pelo presidente que havia o esforço de tentar descaracterizá-la. 0 habeas corpus fora definido por sete ministros e negado por cinco, com a incisiva resposta de Epitácio Pessoa contra Pedro Lessa. À ordem fora negada execução, e apenas uma semana depois de lavrada era tornada sem efeito através de uma declaração assentada por seis ministros contra cinco. Além de o governo não ter cumprido o habeas corpus, o próprio Tribunal veio a anulá-lo, capitaneado por Epitácio Pessoa. E o que mais chama a atenção é a íntegra dos documentos publicados pelo periódico. Não só a sentença foi transcrita, como também o foram a petição inicial, documentos probatórios e atas das sessões posteriores ao julgamento.

E continuava a ênfase sobre a situação, embora apenas com o acórdão. No mesmo volume era publicado o HC 3061, em que um outro presidente da ALERJ, Modesto Alves Pereira de Mello, pedia livre ingresso e locomoção para si e para deputados. A 29 de julho de 1911 o STF concedia a ordem nos termos do HC 2984 anterior, com os votos do vice-presidente Ribeiro de Almeida, do relator, de Oliveira Ribeiro, Manoel Espínola, Manoel Murtinho, Amaro Cavalcanti e Pedro Lessa: os mesmos do caso anterior. Vencidos estavam também os mesmos, ausente Epitácio Pessoa, mas acrescido de Godofredo Cunha, que Ihe prestou defesa.

0 relator Canuto Saraiva explicava no acórdão que a ordem do HC 2984 não teria sido obedecida devido ao Decreto n. 8499 A, de 3 de janeiro de 1911. 0 decreto teria resolvido a questão da dualidade de assembleias, mas só foi publicado no Diário Oficial a 13 de julho de 1911, portanto mais de seis meses depois. Ademais, o decreto só resolvera a questão da dualidade de presidentes do estado, não a de assembleias.

A discussão sobre o decreto recaía sobre a intenção do legislador: "resolver provisoriamente a anormalidade governamental e aguardar que o Congresso Nacional decidisse o caso de dualidade de Assembléas Legislativas". Nessa omissão do Legislativo federal deveria intervir o Judiciário: "Ao Poder Judiciario, porém, não é permitido recusar-se conhecer a face judicial do caso, sob o fundamento da existencia de um projecto de lei em andamento no Congresso Nacional" (O Direito, 1912: 609).

Pedro Lessa redigiu voto de uma página e meia para enfatizar que a ordem do HC 2984 não fora anulada nem perdera eficácia jurídica, e que o Executivo não poderia intervir. Retomava o argumento de anulação da ordem anterior, pois é "elementar em direito judiciario que as sentenças do Poder Judiciario só se reformam pelo mesmo Poder por meio de outras 
sentenças e não por indicações. (...) Um decreto ainda não publicado nenhuma validade tem, o que é corriqueiro" (O Direito, 1912: 611; grifo no original).

Guimarães Natal levantava novamente que julgar o caso implicava examinar a legitimidade dos poderes dos pacientes enquanto deputados, o que não seria possível porque outro grupo se dizia também legitimamente eleito. Tal exame escaparia à competência do STF. Negava o HC ainda porque haveria presunções de legitimidade: a) do voto do Congresso Nacional, com três discussões no Senado e duas na Câmara, reconhecendo a Assembleia; b) do Decreto n. 8499 A, de 3 de janeiro de 1911; c) do acatamento do Judiciário estadual às leis e atos da Assembleia e do presidente; d) "da obediencia do povo do Estado do Rio de Janeiro á sua autoridade" (O Direito, 1912: 612).

Era Godofredo Cunha que em voto de seis páginas fazia as vezes de Epitácio Pessoa. Se o caso, as razões e fundamentos do HC 3061 fossem semelhantes ao HC 2984, não haveria necessidade de conceder o que já fora concedido. A concessão faria um segundo habeas corpus, cuja existência seria negada tanto pelo ministro Ribeiro de Almeida quanto pela doutrina estrangeira, citando Church, Hurd, Kent e Blackstone. A figura da intervenção provisória não era um direito constitucional do presidente da República, mas estaria compreendida nas suas "attribuições discricionarias de alta policia politica" (O Direito, 1912: 615) Considerava formalizados todos os requisitos para a intervenção do Executivo federal: um decreto publicado no Diário Oficia/ baseado no n. 2 do art. 6‥ A legitimidade definida pelo presidente da República e submetida ao conhecimento do Legislativo não poderia ser contestada pelo Judiciário.

Era um argumento perfeitamente político e não jurídico, querendo afastar uma apreciação que já estava a fazer, e envolvendo toda uma compreensão de como deveria funcionar a estrutura política. Estaria a defender a "alta autoridade e prestigio" do STF porque, caso 0 Congresso viesse a legitimar a assembleia Alves Costa, o Executivo federal a reconheceria e o HC do STF cairia em descrédito. Dizia defender o STF ao mesmo tempo que o limitava: "0 poder excepcional do Governo, em matéria de intervenção, como em matéria de estado de sítio, exercido sob o exame immediato do Poder Legislativo, escapa á intromissão judicial" ( 0 Direito, 1912: 617).

Chegava a declarar que o "accórdão é, em resumo, um attentado contra o principio da divisão, harmonia e independencia dos poderes políticos da Republica". E ressuscitava um argumento atribuído por ele a um falecido ministro, que inspirava os defensores da restrição das funções do Judiciário: "Livre-nos da dictadura judiciaria como de qualquer outra; a judiciaria não é menos nociva e perigosa que as outras, si não se apoia na força, reveste enganadoras apparencias de autoridade, illusorias exterioridades de direitos, capazes de exaltar e perverter os sentimentos menos reflectidos." 


\section{Conclusões}

E ventos como a Revolta da Chibata ou as revoltas no Acre e Mato Grosso não foram judicializadas, ou pelo menos não constavam em O Direito. Também não houve notícia sobre o bombardeio a Salvador, de janeiro de 1912. Constavam apenas os decretos que davam anistias. Exceto estes, os acontecimentos eram judicializados, e por mais que fossem por fim resolvidos pelo presidente com sustentação do Congresso, davam solidez cada vez maior, mesmo que longe de unânime, à competência do Judiciário para analisar questões políticas. A delimitação da atuação do Judiciário tendia a ser expandida à medida que a Política dos Estados dava sinais de esgotamento, o que implicava soluções autoritárias acompanhadas proporcionalmente por mais numerosos recursos ao Judiciário.

A própria judicialização de questões era um reflexo da centralidade dos casos e de seus implicados. Os personagens de segunda grandeza eram os que estavam em condições de levantar questões judiciais para tentar através delas intervir na política. Estados como São Paulo ou Minas Gerais mantinham uma coesão interna compatível com o sistema político que montavam, não sendo necessário recorrer à Justiça Federal. Provavelmente suas questões eram resolvidas dentro de seu aparato político-administrativo. Rio de Janeiro, Distrito Federal, Bahia e Amazonas, acrescidos do conflito entre Paraná e Santa Catarina, eram os que, com menor capacidade de articulação coesa entre presidente e Congresso, provocavam o Judiciário.

Todos os juízes tinham suas vinculações políticas, como Octavio Kelly junto a Nilo Peçanha, por exemplo. Mas a situação das oligarquias era muito volátil, o que dificulta mesmo a identificação cabal dessas ligações, numa época em que alianças eram enraizadas ou fragmentadas via telegrama. Se havia vinculações oligárquicas, estas devem ser entendidas enquanto concerto oligárquico, já que as alianças eram instáveis. 0 próprio caso do Distrito Federal mostrava que as partes mudavam de lado ainda no mesmo conjunto dos habeas corpus, passando a arrogar cargos recém-disputados entre grupos rivais. Outro exemplo foi o caso baiano, em que o grupo perseguido poderia recorrer ao senador que apoiava o grupo perseguidor. Ademais, não se podem ignorar os elementos processuais objetivos que, mesmo que não condicionem em definitivo os votos, influenciam pelo menos no nível dos argumentos mobilizáveis para fundamentar o posicionamento.

Assim, pode-se complementar a análise de Andrei Koerner sobre os resultados das votações. Os argumentos elaborados eram o um esforço intelectual para dar uma solução jurídica a problemas políticos, o que forçava os juízes a equacionar suas convicções em direção a um resultado político aceitável. 0 esforço de justificar o porquê de uma decisão se articulava 
intrinsecamente à concepção de como deveria funcionar o concerto oligárquico, e isso leva a compreender os posicionamentos dos ministros mais conforme a fundamentação de seus votos, e menos pelo resultado de um placar. Mesmo que se defenda a instrumentalidade do direito perante os casos políticos, havia um esforço para que os juízes pudessem fundamentar com um mínimo de coerência esses dois aspectos, tanto o político quanto o jurídico. E, aliás, eram tanto políticos quanto jurídicos até mesmo a veiculação de época dos resultados dos julgamentos.

Se o caso do Rio de Janeiro ficou mais extenso é porque nele O Direito se debruçou mais, e de forma mais imediata. Os periódicos jurídicos davam a publicização a ideias, tendências e posicionamentos, fazendo registrar e circular essas concepções. Já os casos da Bahia refletem a estabilidade da Política dos Governadores, permitindo que o STF julgasse os casos repetidamente. No que tange à fonte histórica, O Direito apenas fez registro do caso, sem trazer discussões e fundamentações divergentes - se é que ocorreram. Por fim, os casos de Manaus podem mostrar apenas o julgamento simbólico do HC 2950, mas que esclarece o posicionamento extremamente conservador do ministro Godofredo Cunha, que negava a ordem justamente pelo fato de o efeito não ser concreto. A elegante observação de Amaro Cavalcanti, alertando para o perigo da formação de precedentes, não foi suficiente para Godofredo Cunha. De todo modo, Pedro Lessa fazia registrar critérios ampliativos para o cabimento de habeas corpus. Podem ser apenas minúcias mas, no jogo da produção do direito, até mesmo a notícia de sua produção adquire relevância.

\section{Notas}

1 Discurso pronunciado em 1895 pelo então senador Campos Sales no Senado Federal sobre a possibilidade de intervenção federal no estado de Sergipe, sob a alegação de anomalias no governo estadual. Grifos do original.

2 Como cada estado poderia organizar-se politicamente, alguns estados como a Bahia tinham um senado estadual.

\section{REFERÊNCIAS BIBLIOGRÁFICAS}

CHAVES, André Aparecido Bezerra. A revista da Faculdade Livre de Direito da Cidade do Rio de Janeiro: uma proposta para a identidade jurídica nacional brasileira. Dissertação de Mestrado, Universidade de São Paulo, 2011.

CHORÃO, Luís Bigotte. O periodismo jurídico português do século XIX, páginas de história da cultura nacional oitocentista. Lisboa: Imprensa Nacional, 2002. 
CRUZ, Guilherme Braga da. A Revista de Legislação e Jurisprudência, esboço de sua história. Volume 1. Coimbra: Coimbra Editora, 1975.

DIAS, Sônia. Backer, Alfredo. In: ABREU, Alzira Alves de. (coord.). Dicionário Histórico-Biográfico da Primeira República. RJ: FGV, 2011.

FORMIGA, Armando Soares de Castro. O periodismo jurídico no Brasil do século XIX. História do Direito em jornais e revistas. Curitiba: Juruá, 2010.

GROSSI, Paolo e ANZOATEGUI, Victor Tau (orgs.). La Revista Jurídica en la cultura contemporanea. Buenos Aires: Ediciones Ciudad Argentina, 1997.

GUANABARA, Alcindo. A presidência Campos Sales. Brasília: Editora UnB, 1983.

KOERNER, Andrei. Judiciário e cidadania na constituição da república brasileira (1841-1920). Curitiba: Juruá, 1998.

LESSA, Pedro. Doutrina - Questão de limites entre o Estado de Santa Catharina e o do Paraná - Voto do Sr. Ministro Pedro Lessa. O Direito. Rio de Janeiro, vol. 111, jan./abr. 1910, pp. 573-591.

LYNCH, Christian Edward Cyril. Da monarquia à oligarquia: história institucional e pensamento político brasileiro (1822-1930). São Paulo: Alameda, 2014.

e SOUZA NETO, Cláudio Pereira de. 0 constitucionalismo da inefetividade: a Constituição de 1891 no cativeiro do estado de sítio. In: ROCHA, Cléa Carpi da (coord.). As Constituições brasileiras: notícia, história e análise crítica. Brasília: Editora OAB, 2008.

MARTINHO, Ana Maria. Contributo das revistas jurídicas para a comunicação e criação de conhecimento: uma perspectiva bibliométrica. Tese de Doutorado, Universidade de Alcalá, 2011.

PINTO, Jefferson de Almeida. 0 periodismo e a formação do campo jurídico em Minas Gerais. Varia Historia, Belo Horizonte, vol. 29, n. 50, mai./ago. 2013.

QUADROS, Andréa Novais Soares de. PINHO, Araújo. In: ABREU, Alzira Alves de (coord.). Dicionário Histórico-Biográfico da Primeira República. Rio de Janeiro: FGV, 2011 a.

VIEIRA, Severino. In: ABREU,Alzira Alves de (coord.). Dicionário Histórico-Biográfico da Primeira República. Rio de Janeiro: FGV, $2011 \mathrm{~b}$.

O Direito. Rio de Janeiro, vol. 106, maio/agosto, 1906; vol. 109, maio/agosto, 1909; vol. 111, janeiro/abril, 1910; vol. 119, setembro/dezembro, 1912.

RAMOS, Henrique Cesar Monteiro Barahona. A revista 0 Direito - Periodismo jurídico e política no final do Império do Brasil. Dissertação de Mestrado, UFF, 2009.

REZENDE, Astolpho. Revista do Supremo Tribunal. Revista do Supremo Tribunal. Rio de Janeiro, vol. 1, n. 1, abril de 1914, p. 3.

RODRIGUES, Lêda Boechat. História do Supremo Tribunal Federal: Vol. 1 - Defesa das liberdades civis (18911898). Rio de Janeiro: Civilização Brasileira, 1965.

. História do Supremo Tribunal Federal: Vol. 2 - Defesa do federalismo (1899-1910). Rio de Janeiro: Civilização Brasileira, 1968. 
História do Supremo Tribunal Federal: Vol. 3 - Doutrina brasileira do habeas-corpus (1910-1926). Rio de Janeiro: Civilização Brasileira, 1991.

SILVEIRA, Mariana de Moraes. Revistas em tempos de reformas: pensamento jurídico, legislação e política nas páginas dos periódicos de direito (1936-1943). Dissertação de Mestrado, UFMG, 2013. 